Emmanuel E. Douzinas

\title{
Progressive hemorrhage: administer oxygen or early resuscitation?
}

Received: 24 June 2009

Accepted: 28 June 2009

Published online: 18 July 2009

(C) Springer-Verlag 2009

This editorial refers to the article available at: doi:10.1007/s00134-009-1577-2.

\section{E. E. Douzinas $(\bullet)$}

3rd Department of Critical Care, Medical School, Evgenidion Hospital, University of Athens,

20 Papadiamantopoulou St., 115-28 Athens, Greece

e-mail: edouzin@med.uoa.gr

Tel.: +30-210-7208295

Fax: +30-210-7220540

Hemorrhage is one of the main causes responsible for the impairment of blood flow, with subsequent tissue hypoperfusion and hypoxia. As the circulating blood volume decreases, oxygen consumption $\left(V \mathrm{O}_{2}\right)$ remains constant for a considerable amount of blood loss. When the oxygen delivery $\left(D \mathrm{O}_{2}\right)$ drops below a critical level, i.e. $10 \mathrm{~mL} \mathrm{O} /$ min per $\mathrm{kg}, V \mathrm{O}_{2}$ falls abruptly. This signifies a blood volume loss of approximately $50 \%$, associated with substantial reduction in cardiac output and mixed venous oxygen saturation [1]. At this stage of ischemia, deep tissue hypoxia leads the severely $\mathrm{O}_{2}$-deprived cell to prime for generation of ROS, upon $\mathrm{O}_{2}$ re-entry during reperfusion [2]. Cellular priming consists of ATP depletion, since ATP degrades, reaching the level of hypoxanthine with concurrent xanthine oxidase accumulation. This situation is associated with either absolute $\mathrm{O}_{2}$ restriction (no-flow state) or prolonged $\mathrm{O}_{2}$ debt (low flow state) [3]. The profuse and sudden oxygen re-entry at resuscitation acts as a cofactor, allowing xanthine oxidase to convert hypoxanthine to uric acid. The resulting by-products are superoxide anions $\left(\mathrm{O}_{2}^{-}\right)$and hydrogen peroxide $\left(\mathrm{H}_{2} \mathrm{O}_{2}\right)$, representing the main molecules of the initial oxidative burst [2]. The aforementioned reactive oxygen species, along with the free radicals generated by NADPH oxidase within the neutrophils, attack peroxidating cell membranes. Consequently, ischemia/ reperfusion injury occurs, the global equivalent of which is hemorrhagic shock and resuscitation.

Recently, the importance of limited resuscitation [4-7] has been widely acknowledged. Patients with penetrating truncal trauma, in which resuscitation was delayed, had a higher survival rate to discharge $(70 \%)$ compared with promptly resuscitated patients $(62 \%, P=0.04)$ [4]. Likewise, a systemic review of animal studies [5] has also shown a lower risk of death in animals resuscitated to hypotensive levels than in animals resuscitated to normotensive levels $(P<0.00001)$. The small volume resuscitation with fluids such as hypertonic saline [6] or albumin 25\% [7] has similarly shown a higher survival rate compared with infusion of isotonic fluids.

The approach of attempting to lessen reperfusion injury by adjusting the inspired $\mathrm{O}_{2}$ may apply either before [8] or during [9-12] resuscitation. As far as the first case is concerned, the impact of inspired oxygen concentration on tissue oxygenation $\left(\mathrm{tPO}_{2}\right)$ in the absence of resuscitation was the subject of a study from Dyson et al. [8], published in this issue of the journal. The latter case is represented by hypoxemic resuscitation [9-12]; a process in which hypoxemia is applied during the first few minutes of resuscitation and, as shock reverses, it gradually turns to normoxemia.

In the aforementioned study [8], tissue oxygenation improves at mild (less than 20\%) blood volume losses similarly to normovolemia, in response to higher inspired oxygen admixtures. Adversely, at significant (more than $50 \%$ ) blood volume losses, higher inspired oxygen admixtures lead to precipitous reduction of tissue oxygenation, similar to that of animals breathing in-room air. 
Interestingly, despite the paradox of low $\mathrm{tPO}_{2}$ in the presence of hyperoxemia, two additional precipitating factors occurred in animals breathing high oxygen admixtures, compared to those breathing room-air: higher base deficit and increased arterial lactate levels. It was also shown that $\mathrm{O}_{2}$ therapy during significant hemorrhage intensifies the physiological compensatory responses of vasoconstriction and of blood flow redistribution. Therefore, compared with room-air breathing, high flow, high concentration $\mathrm{O}_{2}$ therapy deteriorates both hemodynamics and tissue/cellular hypoxia, in spite of the significantly higher arterial blood oxygenation. This study provides useful physiological insights, but its applicability in the clinical setting is questionable, given that it is hardly conceivable to manage the shocked victim without resuscitation while being under medical attention. Inherently, an even worse outcome was observed by inducing hypoxemia (breathing at $\mathrm{FiO}_{2}=0.15$ ) without resuscitation; all parameters deteriorated and the animals had an earlier death. Apparently, hypoxemia combined with hypoperfusion accelerated the $\mathrm{tPO}_{2}$ fall considerably. The excessive cellular hypoxia led to cellular priming and earlier energy exhaustion.

However, the aforementioned hypoxemia in progressive hemorrhage should not be confused with hypoxemic resuscitation from hemorrhagic shock. The reason is that when the latter is applied with effective reperfusion, it counteracts cellular priming, reducing oxidative response. It represents another approach to abolishing reperfusion injury by inspired $\mathrm{O}_{2}$ manipulation, but combined with resuscitation in this case. It was tested in individual ischemic organs, such as brain [9] and intestine [10], showing a reduction of oxidative aggression and histopathologic injury. Hypoxemic resuscitation was subsequently tested in hemorrhagic shock and was more effective in restoring the blood pressure and in attenuating the excessive oxidative and inflammatory responses elicited by normoxemic resuscitation [11]. In addition, it was shown that hypoxemic resuscitation was associated with less pulmonary endothelial dysfunction and lung injury than normoxemic resuscitation [12].

During progressive hemorrhage, breathing at $\mathrm{FiO}_{2}=1.0$ instead of $\mathrm{FiO}_{2}=0.21$, turned out to be harmful, due to the particularly low $\mathrm{tPO}_{2}$, as reported [8]. Apparently, to address this paradox, direct molecules (reactive oxygen species) or indirect molecules (malondialdehyde) of oxidative response should have been measured and incorporated into the analysis of the results. Hyperlactatemia, for instance, may be attributed to oxidative hepatic injury, and not to increased hepatic metabolic demand for glutathione synthesis, or excessively low $\mathrm{tPO}_{2}$, as suggested by the authors, for the following reasons: (a) in the studies indicated above [9, 11], since a lower MDA was noticed in the hypoxemically resuscitated animals, less membrane destruction was presumed, permitting a higher degree of mitochondrial integrity and hepatic function for lactate metabolism; (b) lactate did not reach higher levels when resuscitation from hemorrhagic shock was performed under hypoxemic, rather than under normoxemic conditions [9, 11]; and (c) the hypoxemically resuscitated animals attained a higher proportion of reduced to total serum glutathione level, despite the deep hypoxemia $\left(\mathrm{PaO}_{2}=35 \mathrm{mmHg}\right)$ during resuscitation [11].

It seems therefore that high $\mathrm{FiO}_{2}$ and hyperoxemia cannot compensate for the low cardiac output and absence of tissue perfusion. It should also be kept in mind that cardiac output and mixed venous oxygen tension is higher in isovolemic anemia than hypovolemia or hypoxemia [13]. Therefore, it would be interesting to resuscitate animals at different levels of blood volume loss and, by varying $\mathrm{FiO}_{2}$ and measuring oxidative parameters, to determine if the management should mainly lay on $\mathrm{O}_{2}$ therapy or on resuscitation efforts.

\section{References}

1. Nelson DP, King CE, Dodd CL, Schumacker PT, Cain SM (1987) Systemic and intestinal limits of $\mathrm{O}_{2}$ extraction in the dog. J Appl Physiol 63:387-394

2. McCord JM (1985) Oxygen-derived free radicals in postischemic tissue injury. N Engl J Med 312:159-163

3. Douzinas EE, Andrianakis I, Livaditi O, Paneris P, Tasoulis M, Pelekanou A, Betrosian A, Giamarellos-Bourboulis EJ (2008) The level of hypotension during hemorrhagic shock is a major determinant of the post-resuscitation systemic inflammatory response: an experimental study. BMC Physiol 8:15
4. Bickell WH, Wall MJ Jr, Pepe PE, Martin RR, Ginger VF, Allen MK, Mattox KL (1994) Immediate versus delayed fluid resuscitation for hypotensive patients with penetrating torso injuries. N Engl J Med 331:1105-1109

5. Mapstone J, Roberts I, Evans P (2003)

Fluid resuscitation strategies: a systematic review of animal trials. J Trauma 55:571-589

6. Gurfinkel V, Poggetti RS, Fontes B, da Costa Ferreira Novo F, Birolini D (2003) Hypertonic saline improves tissue oxygenation and reduces systemic and pulmonary inflammatory response caused by hemorrhagic shock. J Trauma 54:1137-1145
7. Powers KA, Kapus A, Khadaroo RG, He R, Marshall JC, Lindsay TF, Rotstein OD (2003) Twenty-five percent albumin prevents lung injury following shock/resuscitation. Crit Care Med 31:2355-2363

8. Dyson A, Stidwill R, Taylor V, Singer M (2009) The impact of inspired oxygen concentration on tissue oxygenation during progressive haemorrhage. Intensive Care Med. doi: 10.1007/s00134-009-1577-2 
9. Douzinas EE, Andrianakis I, Pitaridis MT, Karmpaliotis DJ, Kypriades EM, Betsou A, Gratsias Y, Sotiropoulou C, Papalois A, Roussos C (2001) The effect of hypoxemic reperfusion on cerebral protection after a severe global ischemic brain insult. Intensive Care Med 27:269-275

10. Douzinas EE, Kollias S, Tiniakos D, Evangelou E, Papalois A, Rapidis AD, Tsoukalas GD, Patsouris E, Roussos C (2004) Hypoxemic reperfusion after 120 min of intestinal ischemia attenuates the histopathologic and inflammatory response. Crit Care Med $32: 2279-2283$
11. Douzinas EE, Livaditi O, Andrianakis I, 13. Gutierrez G, Marini C, Acero AL, Lund Prigouris P, Paneris P, Villiotou V, Betrosian AP (2008) The effect of hypoxemic resuscitation from hemorrhagic shock on blood pressure restoration and on oxidative and inflammatory responses. Intensive Care Med 34:1133-1141

12. Douzinas EE, Orfanos SE, Livaditi O, Augustatou K, Villiotou V, Kavantzas N, Flevari A, Korkolopoulou P, Roussos C, Patsouris E (2009) Hypoxemic resuscitation prevents pulmonary capillary endothelial dysfunction induced by normoxemic resuscitation from hemorrhagic shock. Crit Care Med 37:869-875
$\mathrm{N}$ (1990) Skeletal muscle $\mathrm{PO}_{2}$ during Appl Physiol 68:2047-2053 hypoxemia and isovolemic anemia. $\mathrm{J}$ 